\title{
Time-course of changes in indirect markers of muscle damage responses following a 130-km cycling race
}

\section{Comportamento das respostas dos marcadores indiretos de dano muscular após uma competição de ciclismo de $130-\mathrm{km}$}

\author{
Patrick Rodrigues ${ }^{\dagger}$ \\ Renata Wassmansdorf \\ Fabiano Macedo Salgueirosa ${ }^{2}$ \\ Sara Gabellone Hernandez \\ Vitor Bertoli Nascimento ${ }^{3}$ \\ Larissa Bobroff Daros \\ Lee Wharton ${ }^{4}$ \\ Raul Osiecki
}

Abstract - The purpose of the present investigation was to identify the effects of a 130$\mathrm{km}$ cycling race on indices of biochemical indirect markers of muscle damage and muscle soreness responses during a 72-hour recovery period. Fifteen endurance-trained male cyclists which were competing for more than 2 years and were involved in systematic training at least of 3 days/wk underwent a collection of indirect biochemical markers of muscle damage (CK, LDH, Myo) and delayed onset of muscle soreness (DOMS), at five different moments of data collection: before (PRE) and immediately after (POST) a $130-\mathrm{km}$ cycling race, and $24,48,72$ hours following the cycling race. CK and LDH plasma concentrations significantly increased POST-race $(p<0.001)$ and remained high throughout the 72 hour recover period (CK: $p<0.05$; LDH: $p<0.001)$. Myo increased significantly POST-race $(p<0.001)$ and returned to the PRE-race values 24 hours thereafter $(p<0.05)$. DOMS increased significantly POST-race $(p<0.001)$ and returned to the PRE-race values at 48 hours after $(p>0.05)$. A $130-\mathrm{km}$ cycling race has a noteworthy effect on indices of biochemical indirect markers of muscle damage and muscle soreness responses, indicating that 72 hour recovery period do not seems to be enough for long-distance cyclist, and reinforce the propositions of scientific literature about the need of a sufficient recovery period for cycling endurance athletes.

Key words: Bicycling; Creatine kinase; L-Lactate dehydrogenase; Myalgia; Myoglobin; Recovery of function.

Resumo - O objetivo do presente estudo foi identificar os efeitos de uma competição de ciclismo de 130-km nos indices de marcadores bioquímicos indiretos de dano muscular e na dor muscular durante um periodo de 72 horas de recuperação. Quinze ciclistas do sexo masculino que estavam em treinamento competitivo por mais de dois anos e que estavam em treinamento sistemático, pelo menos três dias por semana, foram submetidos à coleta de marcadores bioquímicos indireto de dano muscular (CK, LDH e Mioglobina) e dor muscular em cinco momentos distintos de coleta: antes, depois, 24, 48 e, 72 horas após uma competição de ciclismo. A CK e a LDH aumentaram imediatamente após a corrida $(p<0,001)$ e mantiveram-se elevadas durante as 72 horas de recuperação (CK: $p<0,05 ; L D H: p<0,001)$. A Mioglobina aumentou logo após a competição $(p<0,001)$ e retornou aos valores basais 24 horas após $(p<0,05)$. A dor muscular aumentou logo após a competição $(p<0,001)$ e retornou aos valores basais após 48 horas de recuperação $(p>$ $0,05)$. Uma competição de ciclismo de 130-km teve efeitos notáveis sobre os indices de marcadores bioquimicos indiretos de lesão muscular e dor muscular, indicando que um periodo de 72 horas de recuperação pode não ser o suficiente para ciclistas de longa distância, isto também reforça as proposiçôes da literatura cientifica sobre a necessidade de um periodo de recuperação suficiente para os atletas de ciclismo de fundo.

Palavras-chave: Ciclismo; Creatina quinase; L-Lactato eesidrogenase; Mialgia; Mioglobina; Recuperação de função fisiológica.
1 Federal University of Paraná. Center of the Studies of Physical Performance. Curitiba, PR. Brazil

2 University Positivo, Curitiba, PR. Brazil

3 University of Londrina State. Research Laboratory of Biomechanics. Londrina, PR. Brazil

4 Queensland University of Technology. Faculty of Health. School of Exercise and Nutrition Sciences. Brisbane, QLD. Australia

Received: 10 0ctober 2015 Accepted: 21 April 2016 


\section{INTRODUCTION}

Endurance cycling is based on the pursuit of an athlete's optimal performance, it places great demand on various physiological and biochemical aspects ${ }^{1}$, and thus, it is extremely important to be aware of all these variables in order to optimize the athletes' performance ${ }^{2}$. However, the increase in exercise load that accompanies endurance cycling causes muscle damage, fatigue and muscle pain ${ }^{3}$. Because of this, to achieve the greatest possible gains in athletic performance, it is necessary to find the perfect balance between the best training load and a sufficient recovery period ${ }^{4,5}$, even though, the balance between training and overtraining is often very delicate 6 .

There is still a dearth of information about the recovery period required between a resistance training session or competition and a subsequent session, so the mechanisms of muscle damage and its recovery in particular must be identified in order to get the right optimal training effect ${ }^{7}$. Methods to assess exercise-induced muscle injury can be obtained mainly from measurements of concentration of biochemical indirect markers of muscle damage in the blood (e.g., CK, LDH, and Myo), and by subjective muscle soreness by visual analog scale ${ }^{8}$.

The ability of endurance cyclists to fully recover before their next competition or high intensity training session is crucial not only for their performance but also for injury prevention. Furthermore, information on the time-course of changes in biochemical indirect markers of muscle damage and muscle soreness after a single endurance cycling completion is scarce. Considering the context of such concern, the present study is valid as it will provide reliable indicators of muscular damage and its recovery following an endurance cycling race and recovery period. Therefore, the purpose of the present investigation was to identify the effects of a $130-\mathrm{km}$ cycling race on indices of biochemical indirect markers of muscle damage and muscle soreness responses during a 72-hour recovery period.

\section{METHODOLOGICAL PROCEDURES}

\section{Subjects}

Fifteen endurance-trained male cyclists (mean $\pm S D$; age: $27.5 \pm 6.3$ year; height: $177.2 \pm 4.5 \mathrm{~cm}$; weight: $72.3 \pm 5.2 \mathrm{~kg}$; body fat: $8.4 \pm 2.7 \%$; $\mathrm{VO}_{2} \max$ : $62.3 \pm 7.8 \mathrm{~mL} \cdot \mathrm{kg}^{-1} \cdot \mathrm{min}^{-1}$ ) volunteered for this study. All participants were competing for more than 2 years and were involved in systematic training at least of 3 days/wk.

Participants visited the laboratory twice before the experimental protocol and cycling race. During the first visit a comprehensive verbal and written explanation about the benefits and risks of the study were given for all subjects, after this, they signed off the informed consent document institutionally approved. A health history questionnaire and a physical activity readiness Questionnaire (PAR-Q) were also completed and the 
subjects were familiarized with the test procedures of experimental protocol. During the second visit subjects' characterization body weight and height, body fat percentage, and $\mathrm{VO}_{2}$ max were determined. The Research Ethics Committee of the Department of Health Sciences of the Federal University of Paraná, approved this study (protocol: 1256.181.11.11).

\section{Study Design}

Experimental protocol was conducted by five different moments of data collection: before (PRE) and immediately after (POST) the cycling race, and 24, 48, 72 hours thereafter. The PRE-race data collection was performed 24 hours before the cycling race (Fig. 1). Participants were instructed to not to perform any kind of physical exercise from 48 hours prior to the first data collection (PRE-race) until the cycling race and during the 72 hours recovery period beyond the POST-race data collection point. Biochemical indirect markers of muscle damage and delayed onset of muscle soreness (DOMS) were collected at each moment.

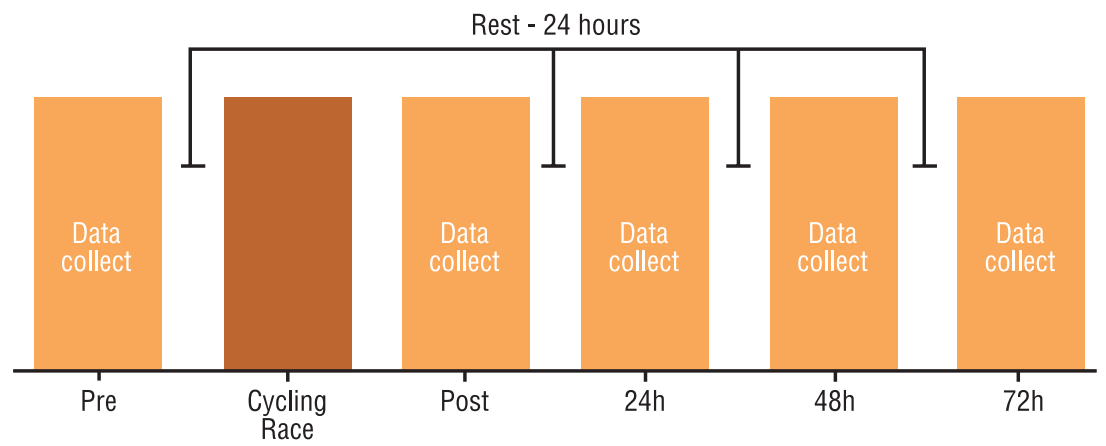

Figure 1. Study Design.

\section{Procedures for data collection}

- Biochemical indirect markers of muscle damage

Blood samples were drawn from an antecubital arm vein using a 20-gauge disposable needle equipped with a Vacutainer tube holder (Becton Dickinson, Franklin Lakes, NJ). The collected samples $(10 \mathrm{~mL})$ were held in Vacutainer tubes containing SST-Gel and a Clot Activator. Samples were separated and analysed according to specialised laboratory conditions for the following variables: Creatine Kinase (CK), Lactate Dehydrogenase (LDH) and Myoglobin (Myo).

Assays: CK activity was determined spectrophotometrically by using a commercially available kit (Spinreact, Sant Esteve, Spain). LDH activity was determined spectrophotometrically by means of commercial diagnostic test kit (Sigma Diagnostics, St. Louis, MO). Myo scores were recorded sing assays for Myoglobin $\mathrm{N}$ latex myoglobin reagents (the Behringwerk AG, Marburg, Germany) for use with Behring Nephelometer.

- Delayed onset of muscle soreness (DOMS)

DOMS was determined by the Visual Analogue Scale (VAS) by Huskis- 
son ${ }^{9}$. The VAS is a psychometric response scale used in this study to determine the subjective muscle soreness. A scale of 0 to 10 , where 0 represents no soreness and 10 the worst possible soreness experienced, was engaged. VAS scores were recorded at the time of contraction of the quadriceps and hamstrings muscle and by a palpation on the muscles belly.

\section{- 130-km Cycling race}

The cycling race happened at the International Racetrack of Curitiba. The circuit contains seven curves to the right, four to the left and five line segments, with the longest being 980 meters. Totaling 3,695 meters long, 15 feet wide, and contains a maximum gap of 4 meters (Fig. 2), where the athletes completed 35 rounds of racing completing a total distance of $130-\mathrm{km}$.

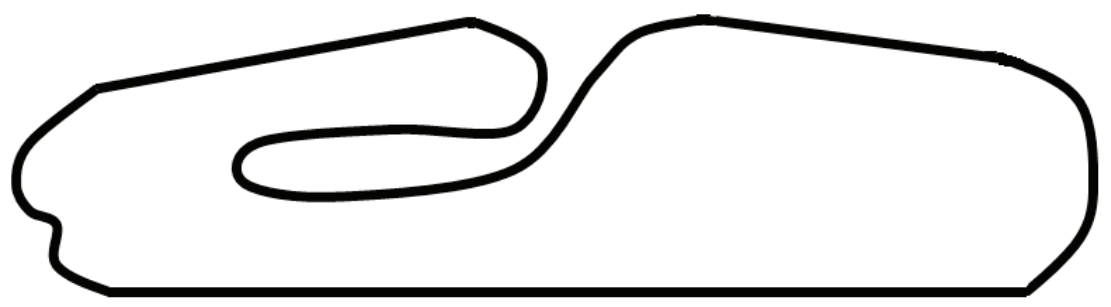

Figure 2. Circuit of International Racetrack.

According to the weather records from SIMEPAR: a local meteorological agency, the cycling race was convened in a temperature of $12.3^{\circ} \mathrm{C}$ and relative humidity of $59.7 \%$, with characteristic of cloudy weather. During the race, hydration and replenishment of energy substrates were determined as free for the cyclists. All participants declared not to be using any medication, supplements containing stimulants and/or anabolic steroids during the race or even for the whole stage of the experimental protocol.

\section{Statistical analysis}

Results are reported as descriptive statistics (Mean \pm Standard Error). The comparison between treatments was done using GEE (Generalized Estimating Equations) at statistical package (IBM SPSS Statistics 20). To determine the level of significance "Wald test" was used and analysis "post-hoc" made by LSD (Least Significant Difference) $p<0.05$. All charts were done by using the software GraphPad Prism ${ }^{\circledR}$ V 5.0.

\section{RESULTS}

The results demonstrate the CK levels increased significantly POST-race $(p<0.001)$. Additionally, results recorded at the 24 hour and 48 hour periods after the race also indicated that the CK levels remained higher that PRE-race and POST-race values $(p<0.05)$. However, results drawn from the 72 hour testing interval demonstrate that while CK levels remain 
higher than PRE-race score they did not show a statistical difference with POST-Race, 24 hour and 48 hour periods after the race (Fig. 3).

Similarly, LDH levels increased significantly POST-race $(p<0.001)$ and remained higher than PRE-race moment values throughout the 72 hours recovery period $(p<0.001) .24$ hours after race LDH remained higher than PRE-race but lower than 72 hours after (Fig. 3).
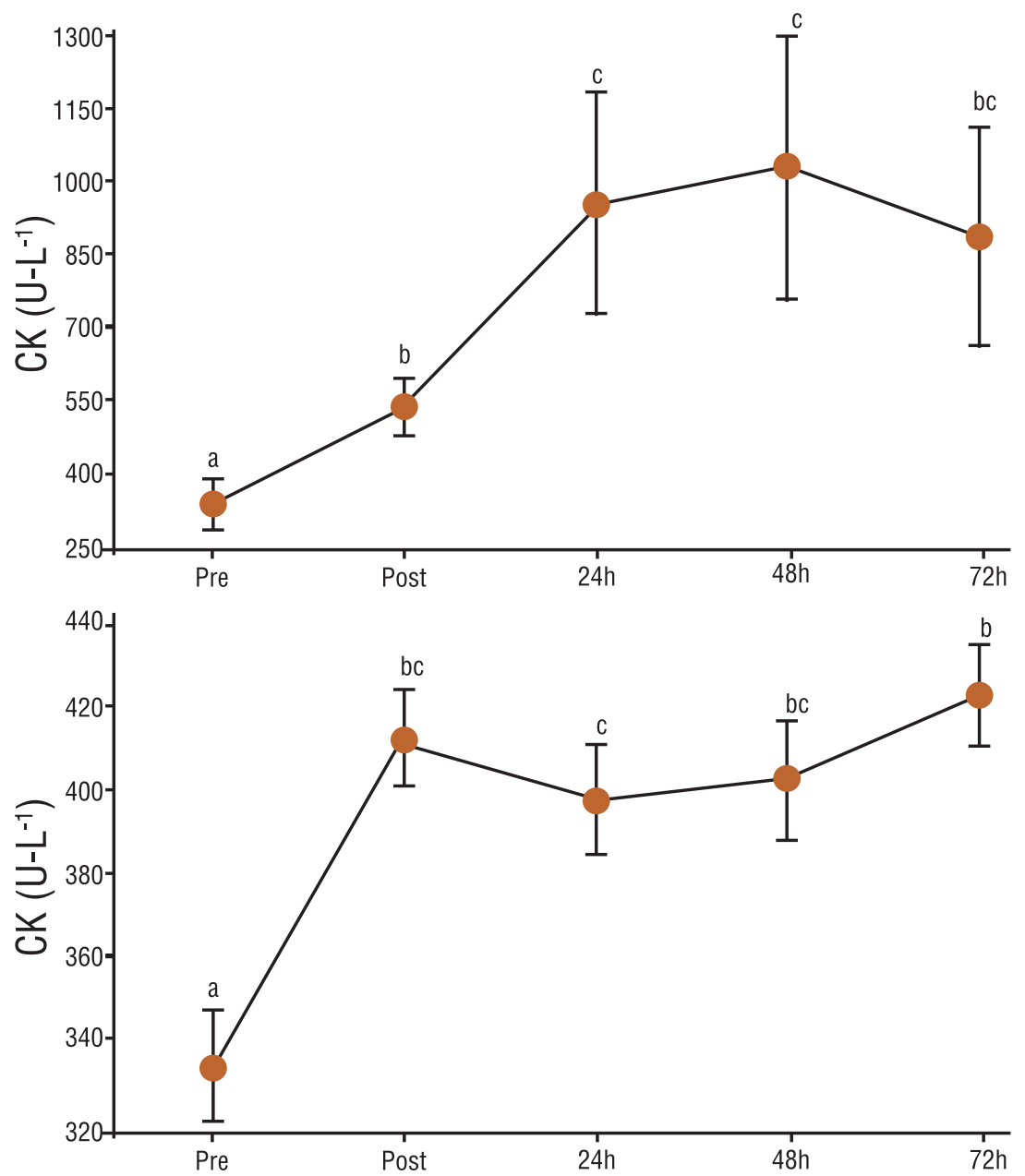

Figure 3. Creatine kinase (CK), and Lactate dehydrogenase (LDH) changes following a cycling race. Values shown as mean \pm SE. Different letters means statistically differences between the moments of data collection $(p<0.05)$. Same letters means no statistically differences between the moments of data collection $(p>0.05)$.

POST-race data collection of Myo was significantly higher than PRErace $(p<0.001)$ and higher than any other moments of data collection $(p$ $<0.001)$. Interestingly, Myo data drawn from the 24 hour, 48 hour and 72 hour intervals after the race demonstrate no difference with PRE-race data, another difference was discovered from 24 hours to 72 hours after the race $(p<0.05)$ (Fig. 4).

Evaluated by the VAS the subjects reported significant increase of DOMS POST-race $(p<0.001), 24$ hours after it was significantly lower than POST-race $(p<0.001), 48$ hours lower than 24 hours after $(p<$ $0.001)$, and 72 hours lower than 48 hours after race $(p=0.003)$. Whereas, 
the moments 48 and 72 hours after the race had no statistic differences compared with the PRE-race moment (Fig. 5).

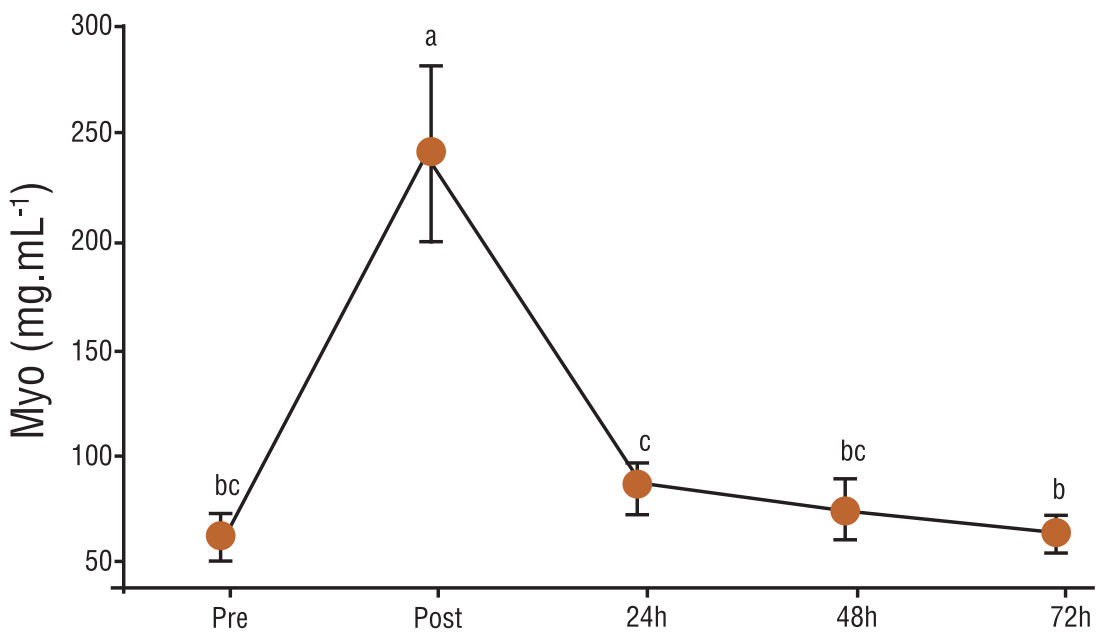

Figure 4. Myoglobin (Myo) changes following a cycling race. Values shown as mean $\pm \mathrm{SE}$. Different letters means statistically differences between the moments of data collection $(p<0.05)$. Same letters means no statistically differences between the times of data collection $(p>0.05)$.

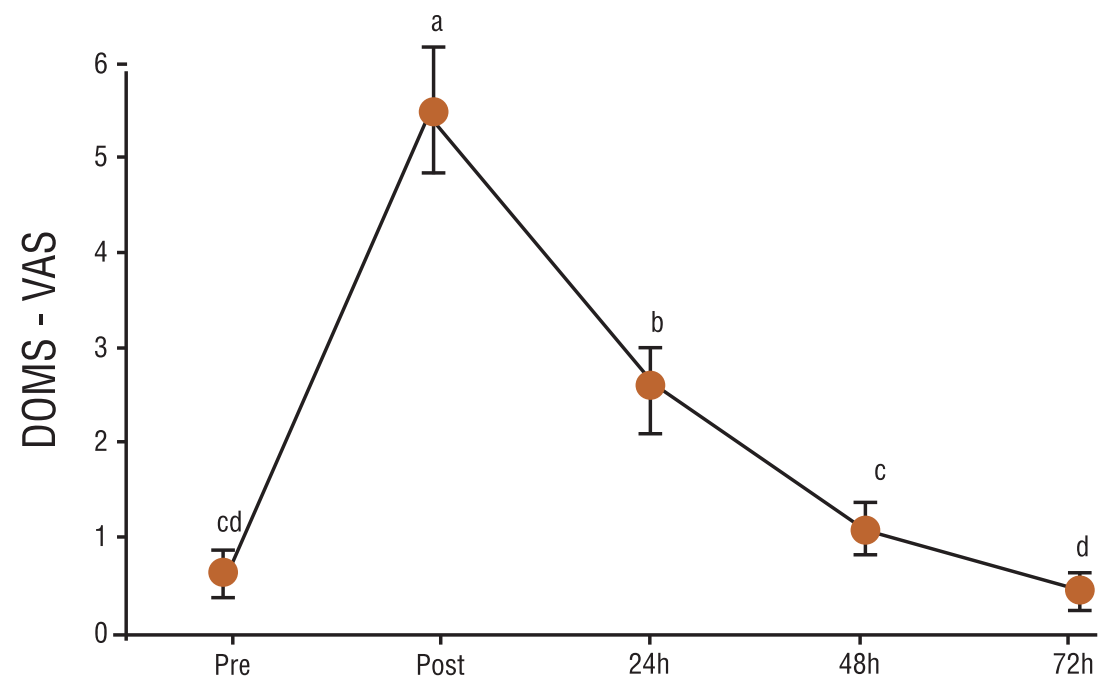

Figure 5. Delayed onset of muscle soreness (DOMS) by the Visual Analogue Scale (VAS) changes following a cycling race. Values shown as mean $\pm \mathrm{SE}$. Different letters means statistically differences between the moments of data collection $(p<0.05)$. Same letters means no statistically differences between the moments of data collection $(p>0.05)$.

\section{DISCUSSION}

The findings of this research shows that a $130-\mathrm{km}$ cycling race has a noteworthy effect on indices of biochemical indirect markers of muscle damage and muscle soreness. Immediately after the race all biochemical indirect markers had increased plasma concentrations, noting that the specific biomarkers $\mathrm{CK}$ and $\mathrm{LDH}$ did not return to baseline values within 72 hours. Furthermore, DOMS increased POST-race and did not returned to baseline values until a 48 hours recovery period had passed.

It is very important to monitor the behavior of biochemical indirect 
markers for muscle damage after strenuous exercise. Increased plasma concentrations of CK, LDH and Myo are specific indicators of muscle damage $^{10,11}$. Furthermore, the knowledge of the behavior of these biomarkers enables scientists, coaches and athletes in the area to better fit their training intensity for both enhancement of sports performance and to prevent the onset of overtraining, thus improving not only athletic performance, but also their health and quality of life $\mathrm{e}^{12,13}$.

CK values will increase significantly immediately after strenuous exercise, even when performed in different modalities such as a soccer game $^{14}$, eccentric exercise protoco ${ }^{15}$, and long distance competitive running (half marathon $-21 \mathrm{~km})^{16}$. Moreover, these levels can remain elevated for up to 96 hours after exercise.

This is similar to the research of Machado et al. ${ }^{17}$ who found significant high levels of CK up to 120 hours after long distance competition (ultra-marathon), this research finding supports assertions of other researchers ${ }^{18,19}$ that says CK serum levels may remain higher from 2 to 7 days after strenuous resistance exercise. In addition, it is known that $\mathrm{CK}_{\text {peak }}$ is usually reached between 24 and 96 hours after exercising ${ }^{15,20,21}$. LDH such as $\mathrm{CK}$, increases its plasma levels after exercise and may remain elevated for up to 72 hours after reaching $\mathrm{LDH}_{\text {peak }} 48$ hours after exercise ${ }^{14}$.

The present investigation supports similar findings in a number of other studies that observed a significant increase of $\mathrm{CK}^{14,16,17}$ and $\mathrm{LDH}^{14}$ plasma levels immediately after strenuous exercise (Fig. 3). Our research also concurs with the earlier works of Ispirlidis et al. ${ }^{14}$ and Machado et al. ${ }^{17}$ concerning the responses of $\mathrm{CK}$ and $\mathrm{LDH}$ plasma concentration levels after exercise and its time-course of changes. As these studies ${ }^{14,17}$ have both reported the $\mathrm{CK}$ and $\mathrm{LDH}$ plasma concentration responses had not returned to pre-exercise levels within a 72 hour recovery period. However, the biomarker concentration peaks in comparison with previously mentioned studies ${ }^{14,15}$ have occurred at different moments in the recovery period. They ${ }^{14,15}$ have found $\mathrm{LDH}_{\text {peak }}$ at 48 hours after and $\mathrm{CK}_{\text {peak }}$ at 96 hours after exercise, while we found $\mathrm{LDH}_{\text {peak }}$ at 72 hours after, and CKpeak at 48 hours after the exercise. What may explain these differences in the results, is the different kind of physical exercise stimulus performed in each study. In this study the control group was exposed to a $130-\mathrm{km}$ cycling race, whereas other studies used a soccer game ${ }^{14}$ and an eccentric exercise protocol ${ }^{15}$.

Modelling studies ${ }^{19,21,22}$ have already shown that these differences occur because the extent of muscle damage caused by exercise is dependent on the intensity and duration of each sports practice and even the experience and training level of each subject. Moreover, the behavior responses of CK after exercise are associated with the biological individuality of athletes, which can classify them as "high-responders" or "low-responders"21,23.

According to Bär et al. ${ }^{18}$, Myo is a more specific biomarker of muscle damage, in this case Bär and colleagues justify such a conclusion based on the fact that unlike CK and LDH, Myo levels increase immediately 
post-exercise and remain so for just the first 24 hours of a recovery period. This report represents an important relationship with the findings of the present research, since Myo have showed to be significantly elevated at the point of POST-race measurement, but showed no significant difference 24 hours after comparing with PRE-race moment (Fig. 4).

In this research the Myo plasma concentration levels showed similar results to a number of other studies ${ }^{12,24}$ which also presented findings that demonstrate significantly increased Myo levels at the moment of postexercise, and even showed $\mathrm{Myo}_{\text {peak }}$ in same moment of data collection ${ }^{12}$.

On the other hand, when compared to the studies of Neubauer et al. ${ }^{12}$ and Ahmadi et al. ${ }^{25}$ about the time-course of changes in Myo after exercise the present investigation found a different result. The researches of Ahmadi et al. ${ }^{25}$ and Neubauer et al. ${ }^{12}$ both have reported higher levels of Myo for up to 2 and 19 days respectively after exercise before returning to pre-exercise values. However, it is worth noting that these studies were performed by a walking on a treadmill protocol (negative inclination) ${ }^{25}$ and an Ironman competition $^{12}$. These differences in post-exercise behavior of Myo can also be supported by the differences between the exercises performed in each study, differing in volume, intensity and the specificity of the mechanics of movement performed.

The delayed onset muscle soreness (DOMS) is also constantly described as an indirect marker of muscle damage induced by exercise $\mathrm{e}^{26-28}$. Two studies ${ }^{15,26}$ observed the muscle soreness after muscle damage induced by eccentric exercise protocol and found similar responses to the DOMS after exercise. DOMS increased significantly during the first 24 hours recovery period, peaked at 48 hours and returned to baseline values 96 hours after exercise in both studies. In the previously mentioned study ${ }^{14}$ which measured the muscle soreness responses following a soccer game found significant increase in DOMS 24 hours later, reaching peak at 48 hours and returning to pre-game values 72 hours after the game.

In the present research, DOMS had a different response after strenuous exercise when compared with the studies cited above. In this study, DOMS had recorded a significant increase and peaked immediately POST-race and remained higher for the 24 hour afterward, but 48 and 72 hours after the race showed no significant statistical difference with PRErace moment (Fig. 5). These differences time-course of change in muscle soreness responses after exercise with other studies could be explained by the specificity of exercise performed in the present study, which differs from the studies above cited.

\section{CONCLUSION}

The results of the present study points out the importance of monitoring the indirect markers of muscle damage by professionals and coaches for better scheduling and planning of training and competition for cycling endurance athletes. All biochemical indirect markers tested in this research 
had increased its plasma concentrations at POST-race measurements, noting that $\mathrm{CK}$ and $\mathrm{LDH}$ did not return to baseline values within 72 hours. Furthermore, DOMS increased POST-race as well and did not returned to baseline values until a 48 hours recovery period had passed. These data provide compelling evidence to suggest that a 72 hour recovery period do not seems to be enough for long-distance cyclist. Moreover, our findings supports the earlier propositions of scientific literature about the need of a sufficient recovery period for these athletes.

This investigation also observed that after long distance cycling competition the indices of biochemical indirect markers and DOMS have a different response in peak time and recovery time comparing with other sports and exercise-induced muscle damage protocol. This alone reinforces the importance of each variable collected in this research and the specificity of each exercise performed. Demonstrating for coaches, trainers and professionals of this area the importance of testing their athletes and comparing results with other research involving same sport subjects and same variables, in order to avoid signs of overtraining and subsequently decrease the rates of injury and fatigue caused by the practice of high intensity sports without an enough rest period.

\section{REFERENCES}

1. Armstrong LE, Johnson EC, McKenzie AL, Ellis LA, Williamson KH. Ultraendurance cycling in a hot environment: thirst, fluid consumption, and water balance. J Strength Cond Res 2015;29(4):869-76.

2. Diefenthaeler F, Candotti CT, Ribeiro J, Oliveira AR. Comparison of absolute and relative physiological responses of cyclists and triathletes. Rev Bras Med Esporte 2007;13(3):205-8.

3. Lieber RL, Shah S, Fridén J. Cytoskeletal disruption after eccentric contractioninduced muscle injury. Clin Orthop 2002;403(1):90-9

4. Capostagno B, Lamberts RP, Lamberts MI. Relationships between submaximal performance parameters over time when endurance cycling performance improves: implications for interpretation of the Lamberts and Lambert submaximal cycle test. Br J Sports Med 2010;44(14):1136-46.

5. Roelofs EJ, Smith-Ryan AE, Melvin MN, Wingfield HL, Trexler ET, Walker N. Muscle size, quality, and body composition: Characteristics of Division I crosscountry runners. J Strength Cond Res 2015;29(2):290-6.

6. Oliveira MFM, Caputo F, Greco CC, Denadai BS. Related aspects of aerobic training optimization for high. Rev Bras Med Esporte 2010;16(1):61-6.

7. Bentley DJ, Smith PA, Davie AJ, Zhou S. Muscle activation of the knee extensors following high intensity endurance exercise in cyclists. Eur J Appl Physiol 2000;81(4):297-302.

8. Prasartwuth O, Allen TJ, Butler JE, Gandevia SC, Taylor JL. Length-dependent changes in voluntary activation, maximum voluntary torque and twitch responses after eccentric damage in humans. J Physiol 2006;571(1):243-52.

9. Huskisson EC. Measurement of pain. The Lancet 1974;304(7889):1127-31.

10. Mackey AL, Bojsen-Moller J, Qvortrup K, Langberg H, Suetta C, Kalliokoski K. et al. Evidence of skeletal muscle damage following electrically stimulated isometric muscle contractions in humans. J Appl Physiol 2008;105(5):1620-7.

11. Malm C, Nyberg P, Engstrom C, Sjodin B, Lenkei R, Ekblom B, et al. Immunological changes in human skeletal muscle and blood after eccentric exercise and multiple biopsies. J Physiol 2000;529(1):243-62. 
12. Neubauer O, König D, Wagner K. Recovery after an Ironman triathlon: sustained inflammatory responses and muscular stress. Eur J Appl Physiol 2008;104(3):417-26.

13. Osiecki R, Rubio TBG, Coelho RL, Novack LF, Conde JHS, Alves CG, et al. The Total Quality Recovery Scale (TQR) as a Proxy for Determining Athletes' Recovery State after a Professional Soccer Match. J Exerc Physiol (online) 2015;18(3):27-32.

14. Ispirlidis I, Fatouros IG, Athanasios Z, Nikolaids MG, Michailidis I, Douroudos A, et al. Time-course of changes in inflammatory and performance responses following a soccer game. Clin J Sport Med 2008;18(5):423-31.

15. Chapman DW, Newton MJ, Zainuddin Z, Sacco P, Nosaka K. Work and peak torque during eccentric exercise do not predict changes in markers of muscle damage. Br J Sports Med 2008;42(7):585-91.

16. Siqueira LO, Muccini T, Agnol LD, Filla L, Mendes PT, Luvison A, et al. Biochemist plasmatic and urinary parameters analysis in marathons athletes. Arq Bras Endocrinol Metab 2009;53(7):844-52.

17. Machado CN, Gevaerd MS, Goldfeder RT, Carvalho T. Effect of exercise on concentrations of serum creatine kinase in triathletes ultra distance. Rev Bras Med Esporte 2010;16(5):378-81.

18. Bär PRD, Reijneveld JC, Wokke JHJ, Jacobs SCJM, Bootsma AL. Muscle damage induced by exercise: nature, prevention and repair. In: Salmons S, editor. Muscle Damage. Oxford: Oxford University Press 1997:1-27.

19. Serrão FV, Foerster B, Spada S. Functional changes of human quadriceps muscle injured by eccentric exercise. Braz J Med Biol Res 2003;36(6):781-6.

20. Mougios V. Reference intervals for serum creatine kinase in athletes. Br J Sport Med 2007;41(10):674-8.

21. Totsuka M, Nakaji S, Suzuki K, Sugawara K, Sato K. Break point of serum creatine kinase release after endurance exercise. J Appl Physiol 2002;93(4):1280-6.

22. Amat AM, Corrales JEM, Serrano FR, Boulaiz H, Salazar JCP, Contretas FH, et al. Role of a-actin in muscle damage of injured athletes in comparison with traditional markers. Br J Sports Med 2007;41(7):442-6.

23. Brancaccio P, Maffulli N, Limongelli FM. Creatine kinase monitoring in sport medicine. Br Med Bull 2007;81(1):209-30.

24. Bailey DM, Erith SJ, Griffin PJ, Dowson A, Brewer DS, Gant N, et al. Influence of cold-water immersion on indices of muscle damage following prolonged intermittent shuttle running. J Sport Sci 2007;25(11):1163-70.

25. Ahmadi S, Sinclair PJ, Davis GM. Muscle oxigenation after dowhill walkinginduced muscle damage. Clin Physiol Funct Imaging 2008;28(1):55-63.

26. Abad CCC, Ito LT, Barroso R, Ugrinowitsch C, Tricoli V. Effect of classical massage on subjective perceived soreness, edema, range of motion and maximum strength after delayed onset muscle soreness induced by exercise. Rev Bras Med Esporte 2010;16(1):36-40.

27. Close GL, Kayani A, Vasilaki A, McArdle A. Skeletal muscle damage with exercise and aging. Sport Med (Auckland) 2005;35(5):413-27.

28. Howatson G, Van SK. The Prevention and treatment of Exercise-Induced Muscle Damage. Sport Med 2008;38(6):483-503.

CORRESPONDING AUTHOR

Patrick Rodrigues.

Rua: João Fernandes Vieira Jr, 250 Ap 101 - Bairro Fazenda. CEP: 88302-600 - Itajaí, SC. Brasil. Email: prof.patrickrodrigues@ yahoo.com.br 